\title{
EL CINE POÉTICO-MÍSTICO DE PARADJANOV Y VAL DEL OMAR. TRADICIÓN CULTURAL Y ETNOGRÁFICA COMO PALIMPSESTO
}

\author{
Elena Galea Pozo \\ (Universidad de Córdoba) \\ egaleapo@gmail.com
}

RESUMEN: El presente artículo sigue las huellas de diferentes manifestaciones literarias en las obras de los cineastas José Val del Omar y Sergei Paradjanov. El cine de ambos es poético, espiritual y místico, y destaca por ser revolucionario en lo que se refiere a la creación de códigos iconográficos — para lo que se valen de textos donde aparecen la tradición cultural etnográfica, el folclore, leyendas populares y doctrinas místicas.

PALABRAS CLAVE: cine experimental, mística, etnografía, poesía, religión, Val del Omar, Paradjanov.

\section{VAL DEL OMAR AND PARAJANOV'S POETIC-MYSTICAL CINEMA. ETHNOGRAPHICAL AND CULTURAL TRADITION AS A PALIMPSEST}

ABSTRACT: The present paper follows the traces of different literary expressions in the works of filmmakers José Val del Omar and Sergei Parajanov. Their cinema is poetic, spiritual and mystical, and it is remarkable for being groundbreaking regarding the creation of iconographic codes through the use of texts where ethnographic cultural traditions, folklore, popular tales and mystical theories are displayed.

KEYWORDS: Experimental cinema, mysticism, ethnography, poetry, religion, Val del Omar, Parajanov.

Las obras cinematográficas de los cineastas José Val del Omar y Serguei Paradjanov comparten ciertos aspectos que constituyen un cine con forma de poesía visual mística y en las que intervienen elementos poéticos y literarios, así como elementos de varias doctrinas místicas (fundamentalmente cristianas y musulmanas) y ciertas técnicas cinematográficas.

Para situar en la historia del cine las obras cinematográficas de ambos cineastas, mencionaremos las más notables, sobre las que centraremos este artículo: Enu氏 qnцjun (Sayat Nova. El Color de la granada, 1969), biopic libre sobre el ashik (poeta-bardo) Sayat Nova del armenio Serguei Paradjanov; y el Tríptico Elemental de España, formado por Aguaespejo granadino (La Gran Siguiriya) (1953-1955), Fuego en Castilla (Táctil-Visión del Páramo del Espanto) (1960) y Acariño Galaico (de barro) (1961-1995) del granadino José Val del Omar.

Una de las conexiones más destacables entre estas obras es la influencia y la representación de la tradición cultural y etnográfica y la identidad de sus respectivos pueblos: España y la zona transcaucásica (Armenia, Georgia, Azerbaiyán, Ucrania y Moldavia). Ambos muestran un especial interés por el folclore popular, la mitología propia y la heredada de pueblos vecinos y pueblos invasores. Además, en la construcción de las identidades de estos pueblos juega un papel esencial la religión, que alberga la mística como manifestación cultural. En palabras del propio Paradjanov, su 
campo de interés se halla en «los problemas a los que nos enfrentamos; en la etnografía, en Dios, en el amor y en la tragedia». ${ }^{1}$ Eduardo Russo (2000: 6) habla sobre esta conexión entre el cineasta armenio y el granadino:

En esa conexión milenaria entre oriente y occidente que es Andalucía, con su epicentro en Granada y su condensación arquitectónica en la Alhambra, VDO [Val del Omar] se ocupa — con tanta pasión como han demostrado algunos de sus pares orientales, como los rusos Tarkovski y Paradjanov o, antes, Dovjenko - de filmar la materia. No por ímpetu científico, sino por un intento de fusión guiado por una mística.

El uso del medio cinematográfico como herramienta para analizar estos temas permite llevar a cabo un estudio exhaustivo del contenido de estos filmes, organizado a modo de capas y que aparece como palimpsestos de otras obras y de otras disciplinas.

La siguiente definición de Genette de los palimpsestos (1989: 495) nos ayuda a comprender nuestra propuesta de denominación de las obras cinematográficas de Paradjanov y Val del Omar como palimpséstica:

Digamos solamente que el arte de «hacer lo nuevo con lo viejo» tiene la ventaja de producir objetos más complejos y más sabrosos que los productos «hechos ex profeso»: una función nueva se superpone y se encabalga a una estructura antigua, y la disonancia entre estos dos elementos copresentes da su sabor al conjunto. [...] Esta duplicidad de objeto, en el orden de las relaciones textuales, puede representarse mediante la vieja imagen del palimpsesto, en la que se ve, sobre el mismo pergamino, cómo un texto se superpone a otro al que no oculta del todo sino que lo deja ver por transparencia.

Los palimpsestos en las filmografías de Val del Omar y Paradjanov tienen su razón de ser en la dialéctica que crean las series de objetos que se repiten en los filmes, que hacen dialogar los planos y las imágenes. Podemos hablar así de «un collage de conceptos apropiados de otros textos y aplicados al nuevo contexto según las necesidades argumentales de cada nuevo propósito» (Viver Gómez, 2010: 32).

\section{ELEMENTOS POÉTICOS Y LÍRICOS}

Según Aristóteles, «la poesía es más filosófica y elevada que la historia, pues la poesía dice más lo universal, mientras que la historia es sobre lo particular» (1974: 158). Debido al gran peso de la poesía tanto en estructuras como en contenido en los filmes de Paradjanov y Val del Omar, seguimos la propuesta de que el cine —al igual que la poesía - puede operar semióticamente respecto a diferentes códigos de forma simultánea. Si tenemos en cuenta el concepto de montaje de Eisenstein y Pudovkin, el cine funciona como un verso: las escenas no se desdoblan en una sucesión, un orden gradual, sino que se reemplazan - se convierten en versos independientes, unidades independientes de medida que van siendo reemplazadas - en un momento determinado (Tinianov, 1981: 93).

Val del Omar y Paradjanov adaptan — desde una perspectiva poética - al medio cinematográfico leyendas populares y folclore oriental y occidental. Mientras sus carreras avanzaban, ambos sintieron la necesidad de explorar los orígenes de sus

\footnotetext{
1 Palabras del director en el documental Paradjanov: A Requiem (Ron Holloway, 1994),
} $00: 24: 53$. 
pueblos más profundamente; por ejemplo, en el caso de Paradjanov aparecen nuevos proyectos para entender los conflictos étnicos entre los pueblos del Cáucaso e investigar la exactitud histórica de la influencia oriental sobre esta región —en la épocasoviética (Cazals, 1993: 29). Además, gran parte del folclore y la mitología occidental es creada a partir de sus homólogos orientales, algo a lo que Val del Omar alude en su «Manifiesto de la Asociación de Creyentes del Cinema»: «de todo desarrollo de abajo arriba y de dentro a fuera, en una tierra que es triple vértice de continentes y de coincidencias fronterizas entre Oriente y Occidente» (Val del Omar, 1992a: 73).

\section{Poesía mecamística}

En lo que se refiere a la reinterpretación etnográfica y mitológica de España, Gubern (2004: 7) describe las influencias del cineasta granadino:

Val del Omar emprendió la tarea de escribir poesía con imágenes fotoquímicas y electrónicas y su perfil le sitúa entre el bricolaje ingenieril de un Edison y la experimentación técnico-formal de un Abel Gance, pero enraizado en el entorno cultural de Manuel de Falla y García Lorca, e instalado en la tradición mística de Teresa de Ávila - cuya frase «el amor es camino de conocimiento» gustaba citar - y la vena poética y reflexiva que empalmaba con san Juan de la Cruz y con María Zambrano.

La denominación de la poesía como mecamística viene del concepto establecido por Val del Omar: «idea filosófica motriz de mi técnica de transmisión emotiva de nuestra cultura», es la «técnica imprescindible, fundamental, esencial para el cinema, vamos a llamarla, por lo que tiene de mecánica y de invisible, meca-mística» (Val del Omar, 2010: 282). Estas palabras recuerdan a la obra de San Juan de la Cruz, cuya influencia es la que más sobresale en la obra valdelomariana: "Creo que es buena hora para el amante poeta místico descalzo ascendiendo con los pasos verticales de su pecho al monte de la alegría» (Val del Omar, en Sáenz de Buruaga y Val del Omar, 1992: 187). Juan Ramón Jiménez, Luis Cernuda o Dámaso Alonso son influencias poéticas confirmadas por Val del Omar, pero destacan como esenciales las figuras de San Juan de la Cruz, Santa Teresa de Ávila y Federico García Lorca.

La obra de San Juan de la Cruz, tanto en poesía como en mística, ejerce la principal influencia mística sobre Val del Omar. El cineasta busca una espiritualidad mística y trascendental a través de varias vías y experiencias donde, además, combina las doctrinas taoísta y sufí con la cristiana. Val del Omar escribió algunos textos inspirados en la obra sanjuanista, como [San Juan de la Cruz] Clave mística a una bioelectrónica española, Noche de San Juan y A la tarde te examinarán en Amor, que resultan esclarecedores para comprender la hermenéutica alrededor de Val del Omar y los elementos místicos. En los poemas mayores de San Juan (Cántico Espiritual, Noche Oscura y Llama de amor viva) están los grandes motivos con los que trabajaba: la noche y la llama, la naturaleza, el agua, la flora y la fauna, y los tópicos de la tradición provenzal y del siglo XVII. De los símbolos que crea San Juan, el de la «noche oscura es el más elaborado de todos [...]. Se nos muestra, en toda su misteriosa desnudez erótica (desnudez ya que elige el camino de la negación espiritual para alcanzar la unión)» (Montero, 2006: 271).

Los temas centrales de la poesía de San Juan son «el amor (representado por el Amado y la esposa, que evoluciona de ser amor-hereos hasta ser amor-divino) y la muerte. Algunos de los temas suelen ir emparejados con su contrario, es decir, la 
temporalidad y la eternidad (también mencionada como abolición del tiempo y representada en la corporeidad) o la ausencia y la presencia» (Andrés Gil, 2004:3). Las siguientes estrofas de Cántico contienen los tópicos mencionados:

14. Mi Amado las montañas,

Los valles solitarios nemorosos,

Las ínsulas extrañas,

Los ríos sonorosos,

El silbo de los aires amorosos.

28. Mi alma se ha empleado

Y todo mi caudal en su servicio.

Ya no guardo ganado,

Ni ya tengo otro oficio,

Que ya solo en amar es mi ejercicio.

Val del Omar rescata la caracterización del rechazo a Dios y a la espiritualidad como ceguera: «Oh lámparas de fuego / en cuyos resplandores / las profundas cavernas del sentido / que estaba oscuro y ciego» (Llama de amor viva, vv. 13-16). Otra representación es la de la metáfora de la unión en Noche oscura: «iOh noche que guiaste! / ¡Oh noche amable más que el alborada!/ ¡Oh noche que juntaste / Amado con amada, / amada en el Amado transformada!». El uso del agua como metáfora es uno de los elementos más importantes, como indica Losada (2010: 112): «heard spoken at the end of Aguaespejo granadino, the stagnant prisoner that culture has tamed is water, one of the metaphors, along with "love" and "God", for the divine in the Tríptico. San Juan's preferred metaphor was also water, as in the well-known verses "Qué bien sé yo la fonte que mane y corre / aunque es de noche"»).

Losada (2010: 110-111) también encuentra la influencia de San Juan en el final de Fuego en Castilla:

The images and sounds evoke the verses of the Song of Songs that are repeated as a metaphor for the moment of mystical encounter with the divine by San Juan in his Cántico espiritual: «Winter is now past, the rain is gone, and the flowers have appeared in our land», as the distortions to the colour and sound produce a defamiliarizing effect, mimicking the sensorial acuity of the coenaesthetic condition.

Como indica Mateo Puig, la poesía de Santa Teresa, a pesar de intentar imitar el camino marcado por San Juan, es desnuda: «En su poema Coloquio de amor dice Teresa que [...] hay que hablar con Él (Dios) sin oraciones compuestas, con palabras, que le contemos las cosas» (Mateo Puig, 2015: 299). Por tanto, Teresa de Ávila comparte los motivos y temas de San Juan pero su estilo es más claro y directo: «Vivo sin vivir en mí, / y tan alta vida espero, / que muero porque no muero» (Vivo sin vivir en $m i$, vv. 1-3). Es la lectura que Santa Teresa hace de San Juan, la afirmación de la mística por excelencia: «el alma más vive donde ama que donde anima», presente en composiciones como Nada te turbe, que resume la contradicción que implica el camino místico del sufrimiento hacia la unión y que enlaza con la fe del propio Val del Omar.

A grandes rasgos, la estructura procesual mística en la obra poética de los místicos castellanos nos muestra que para el ascenso es necesario el descenso, la noche. A la manera de Dante, Santa Teresa y San Juan inician un viaje del que solo conocen el 
destino final, y así como Dante debe bajar y atravesar el infierno, los místicos deben sumergirse en la noche para llegar al «Amado». Val del Omar rescata también de estos autores místicos el folclore castellano, el folclore del «páramo del espanto», ligado al posromanticismo becqueriano, y las creencias medievales.

Por otro lado, la obra de Federico García Lorca está presente en toda la obra valdelomariana tanto en términos formales como en elementos. Ambos comparten temas como el amor, la muerte y el paso del tiempo así como símbolos: el agua, la sangre, la luna y la noche. Así, por ejemplo, la poetización de la naturaleza para representar la forma terrenal y la búsqueda de la celestial acerca a ambos granadinos al ejercicio poético-místico. Rafael Llano Sánchez (2015: 158-160) defiende que Lorca y Val del Omar comparten el duende, comparten «un asombroso universo que funde lo folclórico con lo universal, lo lírico con lo surrealista». Ambos comparten una espiritualidad que se despertó en una educación católica pero que está desligada de ritos habituales, aunque veremos que es frecuente el uso de iconografía religiosa como recurso.

De especial trascendencia e interés en las cinegrafias valdelomarianas son dos obras poéticas y la única obra en prosa de Lorca: Poema del Cante Jondo (1929) - donde el nexo superficial es el pueblo gitano y la cultura popular-, Poeta en Nueva York (1930) e Impresiones y Paisajes (1918). Una sentencia de Lorca abre el filme Fuego en Castilla: «En España, todas las primaveras viene la muerte / y levanta las cortinas», ${ }^{2}$ que el propio Val del Omar (1961) justifica en un texto: «Esta frase [de Federico García Lorca] nos descubre una mecánica invisible en donde nos encontramos sumergidos y, frente a frías luces marchitas, aconseja prender fuego al hombre». En los Textos que informan sobre Fuego en Castilla ${ }^{3}$ se encuentra un fragmento de Impresiones y Paisajes (García Lorca, 1918):

Los santos, héroes románticos del sufrimiento por amor a Dios y a los hombres, no encontraron en la escultura española su encarnación artística. Para afirmarlo no hay más que pasar por las salas del Museo de Valladolid. ¡Horror! Causa pena profunda observar la espantable medianía de la escultura. Es el arte que toca más a la tierra. Los genios de ella llegaron a la primera nota de la escala espiritual. Nunca dieron un acorde.

En Tientos de Erótica Celeste (Val del Omar, 1992b), el poema Respiro en Nueva York recuerda al poemario Poeta en Nueva York:

Un arcángel asciende del aljibe.

Un espacio naufraga en el tiempo.

Mi reloj navega sin manillas.

Casi un silencio de mirtos y granadas.

El duende que se filtra por Manhattan

nos sopla y escapa

por la celosía de los rascacielos.

Otro ejemplo es la presencia e influencia del pueblo gitano a través de símbolos y temas: el agua, la leche (con esta la maternidad), el amor y la pasión, el flamenco. Así,

${ }^{2}$ La cita es una variante del texto de Lorca: «En todos los países la muerte es un fin. Llega y descorre las cortinas. En España no. En España se levantan» (Viver Gómez, 2010: 89).

3 Estos textos están recogidos en el sitio web oficial < valdelomar.com $>$, en el apartado de información complementaria de Fuego en Castilla, en cinegrafías. 
hablamos de la influencia del Poema del Cante Jondo, donde Lorca recoge, entre otros, el poema de la siguiriya gitana, el de la soleá, el de la saeta y el gráfico de la petenera, lo que nos lleva a recordar el título de Aguaespejo granadino: la gran siguiriya. Los siguientes versos de «El paso de la siguiriya», uno de los siete del mencionado $E l$ poema de la siguiriya gitana, evocan el camino místico: ${ }^{4}$ " ¿Adónde vas, siguiriya, / con un ritmo sin cabeza? / ¿Qué luna recogerá / tu dolor de cal y adelfa? / Tierra de luz, / cielo de tierra (vv. 11-15)».

\section{Diálogo lírico}

En la obra cinematográfica de Paradjanov intervienen aspectos populares y folclóricos de la zona del Cáucaso sur, Persia, Irán y Turquía. La Escuela «Poética»o «Arcaica» soviética de los 1960 y los 1970, dentro de la cual se incluye El color de la granada (Paradjanov, 1969), está formada por cineastas «no rusos», cuyos filmes acentúan las particularidades culturales de las repúblicas en las que trabajan. Por lo tanto, los filmes de esta corriente a menudo incluyen folclore, vestidos, artes decorativas y música de grupos étnicos particulares (Oeler, 2006: 480).

El filme emblema de Paradjanov, Sayat Nova - renombrado por la censura como El color de la granada - trata de recrear la vida del poeta-bardo Harutyun Sayatyan (Sayat Nova) (1712-1795), un trovador aclamado por sus canciones de amor escritas en azerí, armenio y georgiano, y celebra la polivalencia etnográfica de esta zona geográfica (Zekiyan, 1997: 338). Sayat Nova trabajó como tejedor y posteriormente se unió a la corte del rey Erekle II de Georgia. En 1770 ingresó en el monasterio de Haghpat, donde más tarde sería asesinado por soldados invasores del sah de Irán.

El ashik (bardo-poeta) canta principalmente sobre el amor, pero también dedica canciones de queja al rey e himnos al cristianismo armenio ortodoxo. El reconocimiento y el culto a Sayat Nova viene de su valor como músico, así como de la vigencia de algunos de los temas que trataba en sus canciones y de los retratos de la cultura de su nación, por lo que genera empatía hacia las generaciones posteriores que viven en su lugar de nacimiento y de trabajo. Dowsett (1997: 3) habla de los motivos de esta empatía: «Sayat Nova obeys the literary convention of his day [...] but through all these clouds of convention, the authentic voice of the lyric poet is clearly audible. It is sincerity of feeling, which finds an echo in the often justifiable melancholy of mankind in general and his compatriots in particular, that ensure his lasting fame».

Dowsett recoge relatos e historias de la supervivencia de estas composiciones en la vida diaria de Armenia y de los armenios (si tenemos en cuenta a aquellos que emigraron en la diáspora de principios de siglo XX tras el genocidio armenio) en los contextos más cotidianos: alguien la tararea mientras pasea, un grupo de señores la canta en un bar, un coro la canta. Es evidente que no se puede luchar contra los cambios a la hora de adaptar una canción a una entonación o a unas cadencias que faciliten su memorización en tiempos posteriores a los que se compuso, pero el mensaje permanece en la memoria cultural, por ejemplo, el proyecto musical para la preservación de la música caucásica «Mountains of Tongues». Musical Dialects from the Caucasus, o los filmes de Paradjanov El color de la granada o Ashik Kerib.

${ }^{4}$ Lorca trabaja en Sonetos del amor oscuro la tradición sanjuanista y los motivos del ejercicio poético místico, añadiendo esta referencia a los temas de su obra, y acercándose — más aún— a Val del Omar. 
Paradjanov utiliza relatos basados en leyendas populares sobre «cuatro territorios [...]: uno es eslavo, otro es "griego", el tercero armenio y el cuarto persa, persa significa musulmán y también [...] los nómadas de [...] Asia Central y los imperios nómadas, Gengis Khan y Tamerlan, [...] la China lejana, Pakistán, etc.» (Pato, 2017: 18). Paradjanov, como Val del Omar, distorsiona elementos compositivos de su cultura local pero trata de conservar la esencia que los caracteriza. La obra del armenio «ofrece, sin duda alguna, uno de los ejemplos más vivos y ricos de la interferencia y la afortunada «sim-biosis» [sic] en la unidad de una síntesis genial de culturas de diferentes orígenes y raíces» (Zekiyan, 1997: 337). Desde los inicios de su carrera cinematográfica, Paradjanov aborda temas como la tradición pastoril, las costumbres del pueblo Hutsul, los ritos y ceremonias como bodas o funerales, los trabajos manuales (textil, orfebrería), la vida de los trabajadores de los koljós, ${ }^{5}$ la juglaría medieval y ashik, y la literatura popular (Sayat Nova) y culta (Shevchenko, Mandelstam) tanto oral como escrita de la zona transcaucásica, entre otros. Rollet explica que la mayoría de sus filmes tienen como base la misma leyenda oral, pero las variantes de cada región geográfica enriquecen el resultado. ${ }^{6}$

El proyecto de fin de estudios de Paradjanov en el VIGK se llamaba Cuento Moldavo (1951). A este proyecto se le añadió metraje tres años después y se convirtió en Andriesh (1954), filme inspirado en la versión ilustrada del poema narrativo Andriesh: Moldavskaia skazka (1946) del escritor moldavo Emilian Bucov. A pesar de que Bucov colaboró en las tareas de guion, la adaptación de Paradjanov difiere del texto original: algunos personajes no aparecen o tienen más relevancia de la que tenían, y algunos elementos fantásticos desaparecen; y aparece el baile regional como elemento imprescindible en las producciones soviéticas (Steffen, 2013: 30). Aun así, Paradjanov ofrece etnografía y folclore.

El filme Sombras de los ancestros olvidados (también conocido como Los corceles de fuego, 1964) se basa en la novela homónima de Mykhailo Kotsiubinsky. La obra de este escritor ucraniano se caracteriza por un trabajado realismo etnográfico, por la presencia del populismo y por un desarrollo psicológico sutil de los personajes. Sombras de los ancestros olvidados (Tini zabutykh predkiv, 1913), su última novela, es una novela etnográfica de corte psicológico sobre las costumbres del pueblo Hutsul. ${ }^{7}$ El relato cuenta la trágica vida de Ivan Paliichuk, centrando la atención del relato en su historia de amor con Marichka Huteniuk, hija del asesino de su padre, quien muere en una riada y a la que Ivan nunca olvida.

En lo que respecta a la adaptación cinematográfica, el tratamiento narrativo del relato sufre cambios: «In contrast to the uncomplicated narrative technique used by Kotsiubynsky in the novel, the film, Shadows of Forgotten Ancestors, is praised for its uncommon approach to narrative cinema» (Nebesio, 2000: 44). La mayor diferencia entre la novela y la transescritura cinematográfica es la identidad del narrador. En la novela, el narrador es un miembro de la comunidad Hutsul que no interviene en la

\footnotetext{
${ }^{5}$ Granja colectiva soviética.

${ }^{6}$ «Tous ses films (même ceux qui appartiennent à l'époque où, dans les studios de Kiev, il devait se plier aux commandes du régime soviétique) mettent, en effet, en scène des légendes populaires véhiculées par la tradition orale. Nombre d'entre elles, d'ailleurs, connaissent des versions différentes en fonction des zones linguistiques. Ainsi le troubadour Kérib» (Rollet, 2003: 216)

${ }^{7}$ El pueblo Hutsul vive principalmente de la agricultura y la ganadería, por lo que profesan un culto pagano a dioses de los bosques representado en magos y hechiceros; proceden de zonas del este de Ucrania con algunos focos de población en países vecinos como Eslovaquia, Rumanía y Polonia (Steffen, 2013: 57-58).
} 
historia (Rubchack, 1981: 79), mientras que en el filme la identidad del narrador es ambigua, su punto de vista y la historia narrada no siguen el modelo clásico ni se establece de forma clara qué personaje podría ser el narrador.

Del mismo modo, La leyenda de la fortaleza de Suram (Paradjanov, 1985), basada en la novela homónima de Chonkadze (1859-1860), y Ashik Kerib, un cuento de hadas turco (Paradjanov, 1988) de Lermontov son relatos basados en leyendas populares que ambos autores escucharon durante sus viajes por la zona transcaucásica.

Paradjanov adaptó el relato La fortaleza de Surami (Suramis tsikhe), la única obra impresa del escritor y lingüista georgiano Daniel Chonkadze, publicado en la revista literaria Tsiskari entre 1859 y 1860 . Inspirado en una leyenda popular georgiana, trata temas que van desde el folclore, la historia, la protesta política y el drama hasta la crítica a la servidumbre y la opresión. A finales del siglo XIX, la literatura georgiana atravesó varios procesos decisivos, como la introducción del marxismo como una herramienta sociológica aunando las tradiciones del realismo literario y las bases del realismo socialista, por lo que este relato fue censurado y hubo de ser ambientado en la Edad Media, aunque las alegorías fueron entendidas por los lectores.

La leyenda de la fortaleza de Suram (1985) expande el precedente que estableció su hipotexto. ${ }^{8}$ Ambos relatos no existirían de no ser por la leyenda popular de la construcción del complejo medieval de la fortaleza de Surami, construido alrededor del siglo XII. El relato, en base a la leyenda, cuenta la historia de Durmishkhan, cómo abandona a su enamorada, Vardo, y su adopción por el rico Osman Aga. Vardo desiste en la búsqueda de su amado y se convierte en vidente mientras que Durmishkhan se casa con otra mujer y hereda la fortuna de su protector. La fortaleza que da nombre al relato aparece años después cuando Vardo revela que, enterrando en el muro a un joven de ojos azules — que será Zurab, el hijo de Durmishkhan—, la estructura de la fortaleza permanecerá intacta ante posibles invasiones. La historia es contada por diferentes narradores, los cuales presentan diferentes enfoques (Efird, 2018: 475). No obstante, a la hora de la adaptación cinematográfica, los intereses e intenciones de ambos creadores no coinciden: «Parajanov's intervention in Daniel Chonkadze's text marginalizes both the historial details and the social overtones, and foregrounds, instead, the elements of regionally specific nation-building mythology» (Radunovic, 2014: 475).

Por otro lado, Ashik Kerib (Paradjanov, 1988) es un cuento transcaucásico sobre las peripecias y tribulaciones de un trovador turco errante basado en el relato corto Ashik Kerib, un cuento de hadas turco (Ashiki Keribi, Turetskaia skazka, 1837) de Lermontov, una de las influencias más destacadas en el sello paradjanoviano, con quien el cineasta armenio comparte el interés y la fascinación por lo popular así como la riqueza cultural y lingüística de la zona caucásica y su contacto con la zona túrquica y persa. Paradjanov también utilizará de la obra del poeta ruso la descripción de paisajes, «la inspiración visual» del Cáucaso (Powelstock, 2011: 209), que escuchó en esta historia en un viaje a Georgia. En la versión de Lermontov, Kerib es un bardo pobre de Tbilisi, enamorado de Magul Megeri, la hija de un rico turco. El joven bardo se propone conseguir una fortuna para casarse con Magul para lo que se embarca en un viaje de siete años mientras esta le espera. Su rival, Kurshud Bek, le roba la ropa y convence a todos de que Kerib ha muerto. Tras años de peripecias y problemas, Ashik Kerib regresa. Esta versión difiere en ciertos aspectos de la de Paradjanov; por ejemplo, la

\footnotetext{
${ }^{8}$ Nos refererimos a hipotexto según la terminología de Genette. Dentro de sus categorías de intertextualidad, Genette propone la hipotextualidad y la hipertextualidad: «entiendo por ello toda relación que une un texto B (que llamaré hipertexto) a un texto anterior A (al que llamaré hipotexto) en el que se injerta de una manera que no es la del comentario» (Genette, 1989:14).
} 
propuesta de matrimonio es rechazada por el padre de Magul Megeri y su viaje dura mil días (Steffen, 2013: 251-252).

\section{OTROS LIBROS: Dios, TAO Y AlÁ}

Uno de los aspectos identitarios de las obras de ambos cineastas es la religión, desde el cristianismo católico y el apostólico ortodoxo hasta el islam e incluso el judaísmo. Paradjanov y Val del Omar se interesan especialmente por los aspectos más abstractos, espirituales y místicos de estas religiones.

La mística inherente a estas obras reside principalmente en el uso y representación de la naturaleza, a través del agua, el fuego y el barro así como de seres vivos - seres humanos y animales - , que remiten constantemente a la mítica y la mitología de la creación del mundo y de la vida. En los primeros minutos de El color de la granada (00:05:16-00:06:10), una voz over narra el mito bíblico de la creación del libro del Génesis:

En el inicio, Dios creó el cielo y la tierra. En el sexto día, Dios dijo: «Ahora crearemos al hombre a mi imagen y semejanza». Y Dios creó al hombre a su imagen. Dios creó al hombre. Y Dios creó al hombre del polvo de la tierra, y le insufló el aliento de la vida y el hombre fue un alma viva. Y Dios puso al hombre que había creado en el jardín del Edén, para que el hombre labrara la tierra y cuidara del jardín. Y el Señor anunció al hombre...

La caracterización como mística de estos filmes nos lleva a proponer la posibilidad de aplicación del esquema del proceso místico (estadios) y la estructura del camino místico cristiano (como se apreciaba en los poemas de San Juan) como posible estructura en los relatos diegéticos de Val del Omar. Paradjanov, por su parte, se ajusta a los textos de la mística cristiana ortodoxa, en especial los Relatos de un peregrino ruso, donde también se sigue un proceso de autoconocimiento pero de corte más ascético. Ambos directores prestan una especial atención a la religión en estos filmes, específicamente al cristianismo: en España a los símbolos del cristianismo católico, y al apostólico (ortodoxo) en la parte soviético-caucásica.

\begin{tabular}{|l|l|}
\hline Estadio Inicial & Estadio Final \\
AUSENCIA & PRESENCIA \\
VACÍO & PLENITUD \\
TENSIÓN TEMPORAL & PRESENTE \\
AMOR HEREOS & AMOR DIVINO \\
RACIOCINIO DISTANCIADOR & IDENTIFICACIÓN MIMÉTICA \\
MEMORIA DOLOROSA & REMEMORACIÓN \\
\hline
\end{tabular}

Esquema del proceso místico

El camino místico se divide estructuralmente en tres partes: la peregrinación, el anuncio de la unión y la unión (aunque dependiendo de la teoría que sigamos la segunda parte puede ser el anuncio o el comienzo mismo de la unión) (Andrés Gil, 2004: 60). Ahora bien, si tratamos de buscar una analogía de esta estructura en los filmes que 
analizamos, en el Tríptico también encontramos, al menos, tres partes. El ejemplo más evidente es Aguaespejo Granadino, donde el relato se organiza en día-noche-día; quizá la analogía latente en Fuego en Castilla compare la vía mística con el relato bíblico. En el caso de Acariño Galaico, el montaje no fue hecho por el propio Val del Omar, aunque se siguieron sus anotaciones. No obstante, existe una evolución desde los elementos más primitivos (que podría leerse desde el relato bíblico del Génesis), el barro y la tierra, que progresivamente se van modelando: las esculturas van formándose y deformándose hasta ser sustituidas por seres humanos de carne y hueso. En El color de la granada pasa algo parecido a Fuego en Castilla, debido a la reminiscencia alegórica bíblica, el relato sigue la vida de Sayat Nova desde la infancia hasta la vejez, donde el protagonista enfrenta la espiritualidad de una manera específica en cada una de las etapas de su vida.

Además de las estructuras que previamente mencionábamos en los filmes, Val del Omar estableció que el sentido del Tríptico comenzaba con Acariño Galaico y acababa con Aguaespejo, con la unión. Por tanto,

This sets up a sequence that follows San Juan's mystic journey from a postlapsarian condition in which the spirit is trapped by the body's attachment to the material in Acariño galaico, through Fuego en Castilla's confrontation with the sufferings of the noche oscura of purgation —or «dereliction», the pain of being abandoned by God [...] - that prepares the viewer for Aguaespejo granadino's mystical union, the encounter with the divine in nature (Losada, 2010: 106).

A pesar de relacionar en primera instancia a Val del Omar con la mística cristiana, el granadino también leía libros de doctrinas orientales tales como el taoísmo (China) y el sufismo (Irán y Oriente Medio), que están presentes en su obra como cineasta, inventor y poeta. Estas doctrinas le proporcionarán una visión más amplia en términos espirituales.

Por ejemplo, Val del Omar toma ideas del taoísmo como el pensamiento 81, «La verdadera sabiduría: el sabio cuanto más da, más tiene», que coincide con la máxima del Padre Manjón que leemos en Aguaespejo granadino: «Matemáticas de Dios, el que más da es el que más tiene». El segundo pensamiento del Tao refuerza esta idea e indica que «los contrarios se suceden» (Tse, 1983: 125). Val del Omar también interpreta este pensamiento de la doctrina china en el poema Tao que se llame Tao ya no es Tao (Val del Omar, 1992: 26-27). En la primera estrofa establece cómo se genera y avanza la vida (y la imposibilidad de dar una definición exacta), que posteriormente desarrolla en el poema como una lucha armoniosa de contrarios:

Definir es errar, confinar, detener, estancar, morir.

Los dictadores contenedores con su no acción actúan

creando ondas, mareas, envases y cataclismos.

El amor y el temor son los dos motores.

Otras ideas del Tao en la obra valdelomariana son las que conducen a la búsqueda de la Unidad y la caracterización de este proceso, por ejemplo, la forma (21. Forma sin forma $)^{9}$ y el movimiento: 47. Cuanto más lejos se va, menos se aprende, 40.

9 «21. Forma sin forma. b) El Tao es un ser oscuro y luminoso. En su oscuridad es luminoso, porque en su interior están las formas. En su luminosidad es oscuro, porque en su interior contiene seres» (Tse, 1983: 110-111). 
Movimiento del Tao. Sobre la idea del movimiento, el Tao dice: «reversivo es el movimiento del Tao», y Val del Omar cierra sus cinegrafias «sin fin», las cuales siguen una progresión lineal pero se repiten infinitas veces haciendo el movimiento circular, «retornante, reversivo». Este movimiento no requiere distancia, a la manera de la mística el camino conduce hacia dentro. Este interior es la «noche oscura» de San Juan y el estado de ceguera previo al éxtasis en el sufismo.

Val del Omar estudia exhaustivamente «tres zonas de España: Andalucía, Castilla y Galicia, que relaciona con los cuatro elementos: agua (Andalucía, Granada), fuego (Castilla), y barro (Galicia)» (González Manrique, 2008: 183). La cercanía a la naturaleza que promulga el taoísmo enlaza con los mitos y los motivos mágicos del folclore y el núcleo etnográfico de estos pueblos. Val del Omar busca un Ser superior que es todo y forma parte de todo, y reconoce que el Tao estudia esto al igual que los místicos españoles hicieran, sin embargo, la mística española bebe directamente de la doctrina sufí.

Ibn Arabi, el máximo exponente de la doctrina sufí en la península, es mencionado en varias ocasiones por el cineasta granadino. El proceso místico sufí, camino de purificación del alma, se caracteriza por ser un ejercicio de búsqueda interior a través de la reflexión y la palabra en busca del amor y del ardor, cuyos seguidores como el mencionado Ibn Arabi o el persa Rumi se consideraban fieles del amor. Las manifestaciones literarias de los místicos sufíes se caracterizan por un lenguaje técnico - que más tarde desaparece en los estadios previos al éxtasis- que está cargado de erotismo, compuesto por elementos como el fuego, las referencias al vino, el agua, la subida hacia un punto elevado (normalmente una montaña), frutos y árboles.

De la misma forma que el Tao proponía, el místico sufí ha de buscar la verdad dentro de sí mismo, dentro de la oscuridad: «La verdad es, por contra, un misterio oculto dentro de las cosas, escondido en su mundo interior» (Adonis, 2008: 187). En esta búsqueda, el propio ardor quema todo alrededor, y en última instancia, el lenguaje desaparece: «puede transmitir una idea sobre ello, o una experiencia sobre su visión y comprensión, pero su transmisión será indirecta en cualquier caso, es decir, a través de la imagen, el símbolo, el signo y la alusión» (Adonis, 2008: 166). Cobran sentido así las alusiones y los códigos dialécticos que hace Val del Omar al fuego y al agua, a arder y amar; por ejemplo, en Aguaespejo Granadino una voz anuncia: «Pero qué ciegas son las criaturas que se apoyan en el suelo, sin saber por qué. Y no encuentran más razón que las que caen de su peso»; o "pero la muerte es... solo una palabra que se queda atrás cuando se ama. El que ama, arde. Y el que arde, vuela a la velocidad de la luz. Porque amar es ser lo que se ama» (Fuego en Castilla). Este amor desgarrador que busca la unión final es resumido por Val del Omar en algunos de sus textos, como la definición del instinto en el Manifiesto: "Yo quería fugarme del negro de los libros. Quería irme hacia la imagen luminosa. Como las mariposas son atraídas por la luz» (Val del Omar, 1992: 83), o en este fragmento procedente de la conferencia «Meridiano del color» (Val del Omar, 1962): «Yo estoy despierto a la Unidad que —en reflexión es blanca - en transparencia es negra. Yo siento que la Unidad fue mi punto de partida y es mi punto de regreso, yo paso por un arco iris. Yo entiendo que la vida se nos ha hecho posible a nosotros, pobres, cojos, mancos, tuertos, gracias a un desgarro de la Unidad».

La figura de Sayat Nova se descifra desde su papel como ashik o trovador, en cuya caracterización aparece también como místico. El primer ashik, Dede Qorqud, ya se define como un músico sabio místico, entroncando con la hipótesis del origen etimológico del término ashik o ashough, que remite al amor místico. El término ashiq (enamorado) aparece por primera vez en las obras del poeta místico turco Ahmad 
Yasavi (1105-1166) cuando designa a los derviches sufíes como «enamorados de la Verdad» (Gründ y Bois, 2008: 6).

Los sufíes seguían un pensamiento que se fundamentaba sobre varios pasajes del Corán y una interpretación alegórica del mismo. En esta doctrina se encuentran trazos de influencias cristianas, del zoroastrismo y del hinduismo. Posteriormente adoptaron conceptos neoplatónicos así como la doctrina plotiniana de la emanación: el mundo, espejo que refleja el ser divino, es mera apariencia. Para escapar de ella, hay que lograr la aniquilación de la propia personalidad en el ser divino, única realidad, y quedar absorto en ella (Mouradian y Venturi, en Sayat-Nova, 2006: 188-189). Paradjanov lee a maestros sufíes como Rumi y utiliza las reminiscencias e influencias de la poesía sufí persa en la obra de Sayat Nova y Lermontov para crear universos cinematográficos de características, motivos e imágenes similares, sobre todo los relacionados con el tópico amoroso representado por la rosa y el ruiseñor, Majnún y Leila, jardines y frutos. Más próximos a las descripciones del éxtasis (representado por el fuego) producido por el amor de Dios son los versos que se escuchan en El color de la granada: « ¿Cómo puedo proteger mis céreos castillos de amor / del calor devorador de vuestras llamas? / Eres fuego, / vestido de fuego...» (00:30:31 - 00:31:48). Como consecuencia, la influencia del sufismo tanto árabe como persa y el montaje de ambas películas, en la línea del montaje de atracciones de Eisenstein, consiguen emular la transmutación mística.

\section{CONCLUSIONES}

A través del recorrido por elementos poéticos, obras líricas y libros de doctrinas místicas del cristianismo, el islam y el taoísmo, descubrimos la gran cantidad de referencias y referentes en los filmes de estos cineastas y, junto con las leyendas y el folclore popular, comprobamos que la tradición cultural y etnográfica es una de las piedras angulares de las cinematografías de Val del Omar y Paradjanov. Las películas interesarán al espectador ya sea por la temática cultural, la antropológica, la cinematográfica, la lúdica o la espiritual debido a su creación como obras que exaltan elementos comunes del imaginario colectivo del público. Algunas de las técnicas cinematográficas que ayudan a la construcción patética ${ }^{10}$ y mística del filme son las desarrolladas por Val del Omar en su laboratorio P.L.A.T. (Picto-Lumínico-AudioTáctil), el desbordamiento apanorámico, la tactilvisión, el cromatacto, el sonido diafónico, así como el uso de Paradjanov del arte pictórico como recurso para componer planos como tableaux vivants, incluso planos-arabescos y planos-miniaturas (Cazals, 1993: 91), sistemas de códigos de color (Shembel, 2009: 200) o principios compositivos escénicos procedentes del teatro, por ejemplo, del kabuki.

A pesar de los elementos comunes en las obras cinematográficas de ambos cineastas, existe una diferencia muy evidente: Val del Omar respeta casi por completo el origen de los mitos y mantiene su esencia, pero Paradjanov los tamiza de manera que lo esencial se entrevé pero no aparece de un modo tan claro como en el caso del cineasta granadino. Así, mientras Paradjanov trata de hacer un collage, Val del Omar busca dar

${ }^{10}$ Cuando hablamos de patetismo o pathos nos referimos al concepto según lo define Bordwell, tomando el montaje de atracciones del teórico y cineasta soviético Sergei Eisenstein: «Dicho simplemente, "el efecto del pathos de una obra consiste en llevar al espectador hasta la situación de éxtasis". [...] Eisenstein insiste en que éxtasis significa "fuera de stasis". Es decir, un estado de embeleso, de sentirse transportado. [...] El éxtasis se convierte en la versión psicologizada de su versión fisiológica anterior a la empatía» (Bordwell, 1999: 226). 
textura a las imágenes, desbordar el volumen y darle una forma donde lo subyacente esté siempre presente sin denostar la composición pictórica y audiovisual de la imagen como elemento cinematográfico técnico. Sin embargo, los dos llevan a cabo un estudio sobre el origen de estas leyendas - formado por episodios míticos y acontecimientos históricos reales-, cuyo núcleo reconstruyen y reinterpretan para crear obras universales que integren el pasado común de estos mitos. Las nuevas interpretaciones de los poemas, canciones y textos religiosos y místicos, así como de los elementos de los mitos y leyendas se convierten en iconos con forma de imágenes cinematográficas que «reinventan» la tradición; por tanto, tienen núcleo etnográfico supeditado a fines estéticos. Aludimos aquí a la licencia creadora que sigue el concepto que Hobsbawm y Ranger denominan «invención de la tradición» (1983).

Como hemos comprobado, el aspecto poético, tanto de las imágenes como de la banda sonora, aparece como un rasgo característico en las obras de los dos cineastas. En la diégesis sonora de El color de la granada se utilizan «cantos, pasajes recitados, exhortaciones, no obstante siempre son señalados por Paradjanov en su diferencia diegética - generalmente en off-como si procediesen de otra dimensión» (Ruiz de Samaniego, 2017: 191). Tigran Mansurian, el compositor de la banda sonora, "propone la creación de efectos sonoros simbólicos asociados a determinadas imágenes como lluvia, viento, con la posibilidad de apertura a la construcción simbólica de cada signo y su uso en la descripción poética» (Copón, 2017: 231-232), por tanto, el conjunto audiovisual es emotivo y patético.

La imagen cinematográfica contiene la imagen real y la imagen evocada, que los cineastas han construido a través del estudio alegórico del mensaje - emotivo - que quieren comunicar. Esto es posible gracias a su «oposición a la idea semiotizante del mundo a través de códigos impuestos por algunas convenciones, de esta forma la base material de las imágenes las liberaría del sistema simbólico a la vez que restauraría su naturaleza específica» (Shembel, 2009: 184). El propio Paradjanov decía que mientras estudiaba en la VGIK a las órdenes de Savchenko y Dovzhenko las tareas consistían en dibujar sus pensamientos y darles una forma plástica. Esto más tarde tendría sentido, como indica Ángel Quintana: «Mientras una de las grandes revoluciones de la pintura moderna ha consistido en resaltar la materialidad de los elementos plásticos que integran la tela, la imagen fotoquímica ha pasado a ser considerada como una imagen que permite un régimen de analogía respecto al mundo, y su materialidad no ha pasado a depender tanto del celuloide que ha dejado impresas sus huellas» (2003: 55). Así, la forma poética nos parece normal en estas obras: las canciones originales de Sayat Nova se cantan en El color de la granada mientras los acontecimientos de la vida del bardo armenio suceden en tableaux vivants; los poemas de Lorca o los de San Juan de la Cruz se materializan en fuentes, cascadas, estanques y expresiones de tallas barrocas. El desarrollo de los relatos diegéticos sigue la forma de un poema épico o, como anteriormente hemos analizado, del camino místico, lo que refuerza su forma poética pero también genera un contenido patético y emotivo creado por la presencia de influencias poéticas y líricas, por la intención personal y la técnica cinematográfica, que convierte estas obras en «todos audiovisuales» plenamente poéticos. 
AMBAVI SURAMIS TSIKHITSA (LA LEYENDA DE LA FORTALEZA DE SURAMI)

Ficha técnica:

Dirección: Sergei Parajanov, Dodo Abashidze

Guion: Vaja Gigashvili, sobre la historia de Daniel Chonkadze

Fotografia: Yuri Klimenko, Sergo Sikharulidze

Música: Jansug Kakhidze

URSS, 1985

Duración: 86 minutos

Producción: Qartuli Pilmi

Ficha artística: Veriko Andjaparidze, Tamari Tsitsishvili, Dudukhana Tserodze, Dodo Abashidze, Sofiko Chiaureli, Zura Kipshidze, Levan Uchaneishvili

PARADJANOV, A REQUIEM

Ficha técnica:

Dirección: Ron Holloway

Guion: Ron Holloway

Fotografía: Thomas Schwan

Música: Urmuli Folklore

Alemania, 1994

Duración: 57 minutos

Producción: Kino Video

Ficha artística: Sergei Parajanov, Sofiko Chiaureli, Melkon Aleksanyan, Vilen Galstyan, Giorgi Gegechkori

ЦВET ГPAHATA (SAYAT NOVA. EL COLOR DE LA GRANADA)

Ficha técnica:

Dirección: Sergei Paradjanov

Guion: Sergei Paradjanov

Fotografía: Suren Shakhbazyan

Música: Tigran Mansurian

URSS, 1969

Duración: 79 minutos

Producción: Armenfilm

Ficha artística: Sofiko Chiaureli, Melkon Aleksanyan, Vilen Galstyan, Giorgi Gegechkori, Spartak Bagashvili, Medea Djaparidze, Hovhannes Minasyan, Onik Minasyan

TIHI ЗАБУTИХ ПРЕДКIB (SOMBRAS DE LOS ANCESTROS OLVIDADOS)

Ficha técnica:

Dirección: Sergei Paradjanov

Guion: Mykhailo Kotsiubynsky, Ivan Chendej

Fotografía: Yuri Ilyenko

Música: Miroslav Skorik

URSS, 1964

Duración: 97 minutos

Producción: Dovzhenko Film Studios Kiev

Ficha artística: Ivan Mikolajchuk, Larisa Kadochnikova, Tatyana Bestayeva, Spartak

Bagashvili, Nikolai Grinko, Leonid Yengibarov, Nina Alisova, Aleksandr Gaj 
TRÍPTICO ELEMENTAL DE ESPAÑA: ACARIÑO GALAICO (DE BARRO)

Ficha técnica:

Dirección: José Val del Omar, Anric Massó

Guion: José Val del Omar

Fotografía: José Val del Omar

Música: José Val del Omar

España, 1961-1995

Duración: 24 minutos

Producción: José Val del Omar, Filmoteca de Andalucía

Ficha artística: Arturo Baltar

TRÍPTICO ELEMENTAL DE ESPAÑA: AGUAESPEJO GRANADINO, O LA GRAN SIGUIRIYA

Ficha técnica

Dirección: José Val del Omar

Guion: José Val del Omar

Fotografía: José Val del Omar

Música: José Val del Omar, Manuel de Falla

España, 1953-1955

Duración: 23 minutos

Producción: José Val del Omar

Ficha artística: Teófilo Martínez, Pepe Albaicín, Juan Gómez Leal, Señorita Chon, Julián Goya, María José Val del Omar y gitanos de Granada.

TRÍPTICO ELEMENTAL DE ESPAÑA: FUEGO EN CASTILLA (TACTILVISIÓN DEL PÁRAMO DEL ESPANTO)

Ficha técnica:

Dirección: José Val del Omar

Guion: José Val del Omar

Fotografía: José Val del Omar

Música: José Val del Omar, Igor Stravinsky, Vicente Escudero

España, 1960

Duración: 17 minutos

Producción: Hermic Films

\section{OBRAS CITADAS}

Adonis (2008), Sufismo y Surrealismo. Nota introductoria y traducción de José Miguel Puerta Vílchez, Guadarrama (Madrid), Ediciones del oriente y del mediterráneo.

Andrés Gil, Carlos M. (2004), La experiencia poética y la experiencia mística en la poesía de San Juan de la Cruz, Maryland, Scripta Humanistica.

Aristóteles (1974), Aristotelous peri poietikes; Aristotelis ars poética; Poética de Aristóteles, trad. Valentí García Yebra, Madrid, Gredos.

Bordwell, David (1999), El cine de Eisenstein. Teoría y práctica, Barcelona, Paidós.

Cazals, Patrick (1993), Serguei Paradjanov, París, Édition de l'Étoile/Cahiers du Cinéma.

Copón, Miguel (2017), «Contaminación», en Alberto Ruiz de Samaniego (coord.), Leyenda de Paradjanov. Ensayos, Santander, Shangrila, pp. 211-260.

Dowsett, Charles (1997), Sayat'-Nova. An 18th century Troubadour. A Biographical and Literary Study, Lovaina, Peeters/Corpus Scriptorum Christianorum Orientalium.

Efird, Robert (2018), «Sergei Parajanov's Differential Cinema», Film Philosophy, 22, pp. 465483.

García Lorca, Federico (1918), Impresiones y Paisajes, Granada, P.V. Traveset. 
García Lorca, Federico (2014), Poema del Cante Jondo, Madrid, EDIMAT Libros.

García Lorca, Federico (2014), Poeta en Nueva York, Madrid, EDIMAT Libros.

Genette, Gérard (1989), Palimpsestos. La literatura en segundo grado, Madrid, Taurus.

González Manrique, Manuel Jesús (2008), Val del Omar. El moderno renacentista. Loja (Granada), Fundación Ibn al-Jatib de Estudios de Cooperación Cultural.

Gründ, François y Bois, Pierre (2008), Azerbaïdjan - Anthologie des Ashiq/ Azerbaijan Anthology of Ashiq/ Azərbaycan - Aşıq Musiqisi Antologiyasi, Francia, INEDIT (Maison des Cultures du Monde) en colaboración con el Ministerio de Cultura y Turismo de la República de Azerbaiyán.

Gubern, Román (2004), Val del Omar, Cinemista, Granada, Diputación de Granada.

Hobsbawm, Eric y Terence Ranger (eds.) (1983), The Invention of Tradition, Cambridge, Cambridge University Press.

Llano Sánchez, Rafael (2015), García Lorca y Val del Omar. La imagen-duende, Valencia, Pre-Textos, Fundación Gerardo Diego.

Losada, Matt (2010), «San Juan de la Cruz in Tactilvisión: The technological mysticism of José Val del Omar's Tríptico elemental de España», Studies in Spanish \& Latin American Cinemas, 7, 2, pp. 101-115.

Mateo Puig, Aurora (2015), «La mística: el encanto sonoro de la poesía de Santa Teresa de Jesús», en Francisco Javier Campos y Fernández De Sevilla (coord.), Santa Teresa y el mundo teresiano del barroco, Madrid, Real Centro Universitario Escorial-María Cristina, pp. 293-306.

Montero, Juan (ed.) (2006), Antología poética de los siglos XVI \& XVII, Madrid, Biblioteca Nueva.

Nebesio, Bohdan Y. (2000), «Questionable Foundations for a National Cinema: Ukrainian Poetic Cinema of the 1960s», Canadian Slavonic Papers/Revue Canadienne des Slavistes, 42, 1-2, pp. 35-46.

Oeler, Karla (2006), «A collective interior monologue: Sergei Parajanov and Eisenstein's Joyceinspired vision of cinema», The Modern Language Review, 101, 2, pp. 472-487.

Pato, Chus (2017), "“Los Frescos de Kiev" y otros metrajes», en Alberto Ruiz de Samaniego (coord.), Leyenda de Paradjanov. Ensayos, Santander, Shangrila, pp. $16-21$.

Powelstock, Daniel (2011), Becoming Mikhail Lermontov. The Ironies of Romantic Individualism in Nicholas I's Russia, Evanston, Northwestern University Press.

Quintana, Ángel (2003), Fábulas de lo visible: el cine como creador de realidades, Barcelona, Acantilado.

Radunovic, Dušan (2014), «Incommensurable distance: versions of national identity in Georgian Soviet cinema», en Sanja Bahun y John Haynes (eds.), Cinema, State Socialism and Society in the Soviet Union and Eastern Europe, 1917-1989. ReVisions, New York, Routledge, pp. 49-73.

Rollet, Sylvie (2003), «Caucase mon beau souci: continuité et fragmentation chez Paradjanov», en Jacques Aumont (dir.), Le Septième Art, París, Léo Scheer, pp. 213225.

Rubchack, Bohdan (1981), «The Music of Satan and the Bedeviled World: An Essay on Mykhailo Kotsiubynsky», en Mikhailo Kotsiubinsky, Shadows of Forgotten Ancestors, by Mykhailo Kotsiubynsky, Littleton, CO, Ukrainian Academic Press, pp. 79-121.

Ruiz De Samaniego, Alberto (2017), «Arabescos de Paradjanov (Leyendo Sayat Nova en compañía de Mallarmé)», en Alberto Ruiz de Samaniego (coord.), Leyenda de Paradjanov. Ensayos, Santander, Shangrila, pp. 169-199.

Russo, Eduardo A. (2000), «Conjeturas sobre Val del Omar. El que ama, arde», $<\underline{\text { http://www.valdelomar.com/sem1.php?lang }=\text { en\&menu act }=1 \& \text { sem1_codi }=10 \& \text { sem2 }}$ codi $=13>$. 
Sáenz de Buruaga, Gonzalo y María José Val del Omar (eds.) (1992), Val del Omar sin fin, Granada, Diputación de Granada.

Sayat-Nova (2006), Odes arméniennes, trads. Elisabeth Mouradian y Serge Venturi, París, L'Harmattan.

Shembel, Daria (2009), The cine-eye goes digital: Vertov, Paradjanov and the "poetic database», Los Ángeles, University of Southern California.

Steffen, James (2013), The Cinema of Sergei Parajanov, Wisconsin, The Wisconsin University Press.

Tinianov, Iuri (1981), «On the Foundations of Cinema», en Herbert Eagle (ed.), Russian Formalist Film Theory, Ann Arbor, Michigan Slavic Publications, pp. 81-100.

Tse, Lao (1983), Tao Te Ching, ed. Carmelo Elorduy, Barcelona, Ediciones Orbis.

Val del Omar, José (1961), «Duende, Furia, Fuego, Meca-Mística, Cubismo Luminoso», Filmespaña, suplemento $\quad \mathrm{n}^{\circ}$. $<$ http://www.valdelomar.com/cine3.php?lang=es\&menu_act=5\&cine1_cod $=6 \&$ cine2 c od $=15 \&$ cine 3 codi $=67>$.

Val del Omar, José (1962), «Meridiano del color en España», en José María Otero (ed.), La nueva frontera del color, Barcelona, Rialp, p. 181.

Val del Omar, José (1992a), «Manifiesto de la Asociación de Creyentes del Cinema» (1935), en Gonzalo Sáenz de Buruaga y María José Val del Omar (eds.), Val del Omar sin fin, Granada, Diputación de Granada, p.73.

Val del Omar, José (1992b), Tientos de erótica celeste (selección y adaptación de Gonzalo Sáenz de Buruaga y María José Val del Omar), Granada, Diputación de Granada.

Val del Omar, José (2010) «Meca-mística del cine», Cinestudio 1, mayo de 1961, en Escritos de técnica, poética y mística, ed. Javier Ortiz-Echagüe, prólogo Santos Zunzunegui, Barcelona, La Central.

Viver Gómez, Javier (2010), Laboratorio Val del Omar: una contextualización de su obra a partir de las fuentes textuales, gráficas y sonoras encontradas en el archivo familiar, [Tesis Doctoral. Universidad Complutense de Madrid], <https://eprints.ucm.es/11163/>.

Zekiyan, Borghos Levon (1997), «L'identité polyvalente dans le témoignage d'un artiste: Sergueï Paradjanov: Réflexions sur le problème de la polyvalence ethnique et culturelle», Acta Orientalia Academiae Scientiarum Hungaricae, 50, 1-3, pp. 337-347. 